Check for updates

Cite this: RSC Adv., 2019, 9, 39304

Received 30th October 2019

Accepted 14th November 2019

DOI: 10.1039/c9ra08922e

rsc.li/rsc-advances

\title{
One-step, high-yield synthesis of $\mathrm{g}-\mathrm{C}_{3} \mathrm{~N}_{4}$ nanosheets for enhanced visible light photocatalytic activity
}

\author{
Liyan Wang, (D) $\dagger^{a}$ Yangwen Hou, $\dagger^{\mathrm{a}}$ Shanshan Xiao, ${ }^{a} \mathrm{Fei} \mathrm{Bi}^{\mathrm{a}} \mathrm{Li}_{\mathrm{Zhao}}{ }^{a}$ Yingqi Li, (D) ${ }^{a}$ \\ Xiaojia Zhang, ${ }^{a}$ Guangqing Gai*a and Xiangting Dong (DD *b
}

\begin{abstract}
A facile template-free one-step synthesis method of ultrathin $\mathrm{g}-\mathrm{C}_{3} \mathrm{~N}_{4}$ nanosheets was developed through thermal polycondensation of melamine. The higher temperature, prolonged time and tightly sealed crucible reaction system contributed to the formation of ultrathin $\mathrm{g}-\mathrm{C}_{3} \mathrm{~N}_{4}$ nanosheets. The as-synthesized g- $\mathrm{C}_{3} \mathrm{~N}_{4}$ nanosheets were applied to the visible light photocatalytic degradation of RhB. The photocatalytic activity was significantly enhanced with increased calcination temperature from $500^{\circ} \mathrm{C}$ to $650{ }^{\circ} \mathrm{C}$ and prolonged calcination time from $4 \mathrm{~h}$ to $10 \mathrm{~h}$. Interestingly, the obtained ultrathin $\mathrm{g}-\mathrm{C}_{3} \mathrm{~N}_{4}$ nanosheets simultaneously possess high yield and excellent photocatalytic activity. Moreover, g- $\mathrm{C}_{3} \mathrm{~N}_{4}$ nanosheets can maintain photochemical stability after five consecutive runs. The remarkably enhanced photocatalytic activity can be interpreted as the synergistic effects of the enhanced crystallinity, the large surface area, the reduced layer thickness and size and the reduced number of defects. A new layer exfoliation and splitting mechanism of the formation of the ultrathin nanosheets was proposed. This work provides a new strategy to develop a facile eco-friendly template-free one-step synthesis method for potential largescale synthesis of ultrathin nanosheets with high yield, high photocatalytic efficiency and stable activity for environmental and energetic applications.
\end{abstract}

\section{Introduction}

Visible-light photocatalysts have attracted enormous attention worldwide owing to their potential applications in organic pollutant degradation and hydrogen evolution. ${ }^{1-9}$ As a metalfree polymer semiconductor, graphitic carbon nitride $\left(g-\mathrm{C}_{3} \mathrm{~N}_{4}\right)$ is regarded as a promising visible-light photocatalyst due to its reliable chemical and thermal stability. ${ }^{3-6}$ To our knowledge, many strategies have already been developed to improve the activity of $\mathrm{g}-\mathrm{C}_{3} \mathrm{~N}_{4}$, such as introducing metallic or nonmetallic elements, ${ }^{10-14}$ construction of a g- $\mathrm{C}_{3} \mathrm{~N}_{4}$-based heterojunction ${ }^{15-17}$ and controlling the morphology. ${ }^{18-21}$ The morphological structure of $\mathrm{g}-\mathrm{C}_{3} \mathrm{~N}_{4}$ significantly affects its performance. In general, g- $\mathrm{C}_{3} \mathrm{~N}_{4}$ with favorable nanoarchitecture necessarily exhibits prominent activities in practical applications. ${ }^{21}$ At present, the morphological structure of $\mathrm{g}-\mathrm{C}_{3} \mathrm{~N}_{4}$ includes bulk, three dimensional (3D), ${ }^{22,23}$ two-dimensional (2D), one-dimensional (1D), ${ }^{24,25}$ and zero-dimensional (0D) nanostructures. ${ }^{26}$ The

\footnotetext{
${ }^{a}$ Key Laboratory of Building Energy-Saving Technology Engineering, College of Materials Science and Engineering, Jilin Jianzhu University, Changchun, $P . R$. China. E-mail: gaigq@163.com; Fax: +86-431-84566095; Tel: +86-431-84566095

${ }^{b}$ Key Laboratory of Applied Chemistry and Nanotechnology at Universities of Jilin Province, Changchun University of Science and Technology, Changchun, P. R. China. E-mail: dongxiangting888@163.com; Fax: +86-431-85383815; Tel: +86-431-85582574 $\dagger$ Co-first authors.
}

different morphological structure can be controlled by employing different species and ratios of precursors, condensation temperature, exfoliation and doping methods, and different templating strategies, et al. ${ }^{6}$

As is known to all, bulk $\mathrm{g}-\mathrm{C}_{3} \mathrm{~N}_{4}$ photocatalysts possess low photocatalytic activity due to its small surface area and high recombination rate of photo-generated electron-hole pairs. Since the discovery of graphene, two-dimensional (2D) nanosheets, especially with molecular thickness, have attracted more and more attention in heterogeneous photocatalysts. ${ }^{27-34}$ These nanosheets possess exceptional electronic structures feature of 2D anisotropy with nanometer thickness, resulting in distinctive physicochemical properties owing to the quantum confinement effect (QCE). ${ }^{35}$ Considering that the layer of $g-\mathrm{C}_{3} \mathrm{~N}_{4}$ is composed of $\mathrm{C}-\mathrm{N}$ bonds, and weak van der Waals force exists between the layers, researchers fabricated mono or a few layer $\mathrm{C}_{3} \mathrm{~N}_{4}$ sheets by the exfoliation of layered $\mathrm{g}-\mathrm{C}_{3} \mathrm{~N}_{4}$ to improve its photocatalytic activity. ${ }^{6}$

Recently, considered as an effective pathway to prepare the ultrathin $2 \mathrm{D}$ nanosheets of $\mathrm{g}-\mathrm{C}_{3} \mathrm{~N}_{4}$, the liquid exfoliation technology is developed rapidly. Zhang et al. prepared successfully ultrathin $\mathrm{g}-\mathrm{C}_{3} \mathrm{~N}_{4}$ nanosheets by water exfoliation from bulk g$\mathrm{C}_{3} \mathrm{~N}_{4} \cdot{ }^{27} \mathrm{Xu}$ et al. obtained g- $\mathrm{C}_{3} \mathrm{~N}_{4}$ nanosheet with a single atomic thickness of $0.4 \mathrm{~nm}$ by a simple chemical exfoliation method. ${ }^{28}$ Lin et al. prepared monolayer $\mathrm{C}_{3} \mathrm{~N}_{4}$ nanosheet by the pyrolysis of melamine at $550{ }^{\circ} \mathrm{C}$ for $4 \mathrm{~h}$, mixed solvent exfoliation and 
ultrasonic dispersion of $10 \mathrm{~h} .{ }^{29}$ Tong et al. developed g- $\mathrm{C}_{3} \mathrm{~N}_{4}$ nanosheet with high yield via a moderate exfoliation method using diluted $\mathrm{H}_{2} \mathrm{SO}_{4}$ suspension of bulk g- $\mathrm{C}_{3} \mathrm{~N}_{4} \cdot{ }^{30}$ In addition, the thermal exfoliation is considered to be another effective method of preparing the ultrathin 2D nanosheets from bulk $\mathrm{g}$ $\mathrm{C}_{3} \mathrm{~N}_{4}$. Dong et al. synthesized porous $\mathrm{g}-\mathrm{C}_{3} \mathrm{~N}_{4}$ nanosheets via direct pyrolysis of thiourea followed by a thermal exfoliation. ${ }^{31}$ Niu et al. synthesized $\mathrm{g}-\mathrm{C}_{3} \mathrm{~N}_{4}$ nanosheet with a thickness of around $2 \mathrm{~nm}$ by thermal oxidation etching of bulk $\mathrm{g}-\mathrm{C}_{3} \mathrm{~N}_{4}$ in air. ${ }^{32}$ Qiu et al. synthesized g- $\mathrm{C}_{3} \mathrm{~N}_{4}$ nanosheet by exfoliating bulk g- $\mathrm{C}_{3} \mathrm{~N}_{4}$ with a thermal treatment under $\mathrm{H}_{2} \cdot{ }^{33}$ Liang et al. prepared holey $\mathrm{g}-\mathrm{C}_{3} \mathrm{~N}_{4}$ nanosheets with abundant in-plane holes by thermally treating bulk g- $\mathrm{C}_{3} \mathrm{~N}_{4}$ under an $\mathrm{NH}_{3}$ atmosphere. ${ }^{34}$ From the above literature reports, we can draw such a conclusion that the preparation method of ultrathin nanosheets of $\mathrm{g}-\mathrm{C}_{3} \mathrm{~N}_{4}$ consists of two steps generally. At first, the bulk g- $\mathrm{C}_{3} \mathrm{~N}_{4}$ is prepared by thermal polymerization of organic precursors; then ultrathin nanosheets are prepared by the liquid exfoliation and ultrasonic dispersion, or the thermal exfoliation at a certain atmosphere.

In order to simplify the experimental conditions and steps, further realize large-scale production of the ultrathin $\mathrm{g}-\mathrm{C}_{3} \mathrm{~N}_{4}$ nanosheets, researchers developed one-step synthesis methods by using self-supporting or additive atmosphere as bubble template. For example, Liu et al. synthesized $\mathrm{g}-\mathrm{C}_{3} \mathrm{~N}_{4}$ by the simple thermal pyrolysis of urea without additive assistance, but a typical yield of the powder was only $4 \mathrm{wt} \%{ }^{36}$ Dong et al. synthesized porous $\mathrm{g}-\mathrm{C}_{3} \mathrm{~N}_{4}$ nanosheets by direct pyrolysis of urea by a template-free through prolonging the pyrolysis time. ${ }^{37}$ But the corresponding yield of $\mathrm{g}-\mathrm{C}_{3} \mathrm{~N}_{4}$ did not be mentioned. As a low-cost and abundant industrial material, urea is regard as an active precursor for preparing porous $\mathrm{g}-\mathrm{C}_{3} \mathrm{~N}_{4}$. However, this method has a drawback of the low yield, which would limit its practical application. Zhang et al. prepared porous $\mathrm{g}-\mathrm{C}_{3} \mathrm{~N}_{4}$ with yield of $18 \%$ by pyrolysis of dicyandiamide precursor using urea as bubble template. ${ }^{38} \mathrm{He}$ et al. synthesized uniform porous g$\mathrm{C}_{3} \mathrm{~N}_{4}$ through thermal condensation of melamine using sublimed sulfur as soft-template agent, yet the yield was not reported. ${ }^{39}$ Mahalingam et al. synthesized $g-\mathrm{C}_{3} \mathrm{~N}_{4}$ by one-step pyrolysis reaction of melamine in a semi-sealed alumina crucible, the obtained $\mathrm{g}-\mathrm{C}_{3} \mathrm{~N}_{4}$ and $n-\mathrm{Bu}_{4} \mathrm{~N}^{+} \mathrm{Br}^{-}$combination was used for epoxide to cyclic carbonate conversion. ${ }^{40}$ Song et al. synthesized $\mathrm{g}-\mathrm{C}_{3} \mathrm{~N}_{4}$ by heating urea at $550{ }^{\circ} \mathrm{C}$ for $4 \mathrm{~h}$ at a heating of $5{ }^{\circ} \mathrm{C} \mathrm{min}^{-1}$, UV-visible photocatalytic activity was studied, but visible photocatalytic activity was not studied. ${ }^{\mathbf{4 1}}$

Although variety of strategies have been employed to get g$\mathrm{C}_{3} \mathrm{~N}_{4}$ nanosheets, how to synthesize $\mathrm{g}-\mathrm{C}_{3} \mathrm{~N}_{4}$ nanosheets with high yield and high photocatalytic activity simultaneously is far from satisfactory. In the present work, we developed a facile template-free one-step synthesis method of ultrathin $2 \mathrm{D} \mathrm{g}-\mathrm{C}_{3} \mathrm{~N}_{4}$ nanosheets through thermal polycondensation of melamine. The formation of $2 \mathrm{D}$ g- $\mathrm{C}_{3} \mathrm{~N}_{4}$ nanosheet depends mainly on the high calcination temperature, the prolonged calcination time and tightly sealed reaction system. The microstructure, crystal structure and chemical composition, optical property and surface area of as-prepared g- $\mathrm{C}_{3} \mathrm{~N}_{4}$ were characterized in detail. The photocatalytic activity of $\mathrm{g}-\mathrm{C}_{3} \mathrm{~N}_{4}$ nanosheets were systematically investigated by degradation of $\mathrm{RhB}$ under the visible light irradiation. Satisfactorily, ultrathin $\mathrm{g}-\mathrm{C}_{3} \mathrm{~N}_{4}$ nanosheets with excellent photocatalytic activity and high yield of $25 \%$ were obtained successfully at $650{ }^{\circ} \mathrm{C}$ for $10 \mathrm{~h}$. A new layer exfoliation and splitting mechanism was also proposed.

\section{Experimental sections}

\section{Synthesis of $\mathrm{g}-\mathrm{C}_{3} \mathrm{~N}_{4}$ nanosheets}

The $\mathrm{g}-\mathrm{C}_{3} \mathrm{~N}_{4}$ nanosheets were synthesized via directly heating melamine with a facile template-free one-step synthesis method. A certain mass of melamine was placed in an alumina crucible covered with its alumina lid, and was wrapped with aluminum foil. Then the whole was put in a muffle furnace and heated to a certain temperature $\left(500{ }^{\circ} \mathrm{C}, 550{ }^{\circ} \mathrm{C}, 600{ }^{\circ} \mathrm{C}, 650{ }^{\circ} \mathrm{C}\right.$ and $\left.700^{\circ} \mathrm{C}\right)$, and kept for a certain time $(4 \mathrm{~h}, 6 \mathrm{~h}, 8 \mathrm{~h}$ and $10 \mathrm{~h})$ in air, heating ramp is $1{ }^{\circ} \mathrm{C} \mathrm{min}^{-1}$, followed by cooling down to $200{ }^{\circ} \mathrm{C}$ at a cooling rate of $1{ }^{\circ} \mathrm{C} \mathrm{min}^{-1}$ before natural cooling down to room temperature. The resulting samples were marked as $\mathrm{S}_{600-4}, \mathrm{~S}_{600-6}, \mathrm{~S}_{600-8}, \mathrm{~S}_{600-10}, \mathrm{~S}_{500-10}, \mathrm{~S}_{550-10}, \mathrm{~S}_{650-10}$ and $\mathrm{S}_{700-10}$, respectively. In addition, in order to further study the effect of sealing system on the yield of sample, we performed the preparation of $\mathrm{g}-\mathrm{C}_{3} \mathrm{~N}_{4}$ from melamine in an alumina crucible covered with a lid without aluminum foil wrapped at $650{ }^{\circ} \mathrm{C}$ for $10 \mathrm{~h}$ at ramping rate of $1^{\circ} \mathrm{C} \mathrm{min}^{-1}$. The sample was marked as $\mathrm{S}^{\prime}{ }_{650-10}$. Fig. 1 shows that pictures of the sealed crucible before reaction and $\mathrm{g}-\mathrm{C}_{3} \mathrm{~N}_{4}$ sample $\mathrm{S}_{650-10}$ in crucible.

\section{Characterization}

The crystal structures of as-prepared samples were identified by power X-ray diffraction (XRD) on a Rigaku Ultima IV X-ray diffractometer at $40 \mathrm{kV}$ and $40 \mathrm{~mA}$ with $\mathrm{Cu} \mathrm{K}_{\alpha}$ radiation $(\lambda=$ $1.5406 \AA)$. The morphologies and structures were determined using environmental scanning electron microscope (ESEM) on an XL-30 ESEM-FEG from FEI Company and transmission electron microscope (TEM) on a FEI TECNAI F20 S-TWIN electron microscope operated at an accelerating voltage of $200 \mathrm{kV}$. In addition, the morphology and thickness of the nanosheet were characterized by using a Bruker Icon Dimension a tappingmode atomic force microscopy (AFM) on the mica substrate. Fourier transform infrared (FT-IR) spectra of the samples were obtained on a Nicolet iS5 Fourier transform infrared

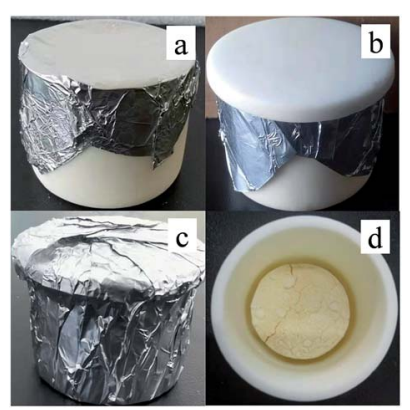

Fig. 1 Pictures of the sealed crucible before reaction $(a-c)$ and $g$ $\mathrm{C}_{3} \mathrm{~N}_{4}$ sample $\mathrm{S}_{650-10}$ in crucible (d). 
spectrometer at a resolution of $4 \mathrm{~cm}^{-1}$ between 4000 and $400 \mathrm{~cm}^{-1}$. The chemical compositions were investigated by using X-ray photoelectron spectroscopy (XPS) on a Thermo ESCALAB 250 instrument with an Al-K $\alpha$ X-ray radiation. UV-vis diffuse reflection spectra (DRS) were obtained on a TU-1900 Scan UV-vis spectrophotometer equipped with an integrating sphere assembly, using $\mathrm{BaSO}_{4}$ as reflectance sample. The photoluminescence spectra (PL) of the samples were surveyed with a F98 fluorescence spectrophotometer made by Shanghai Lengguang Technology Company with an excitation wavelength at $328 \mathrm{~nm}$. Nitrogen adsorption-desorption isotherms were obtained on a ASAP 2020 (V4.01) nitrogen adsorption apparatus from USA, with all samples degassed at $30{ }^{\circ} \mathrm{C}$ and a vacuum of $10^{-3}$ mbar for $6 \mathrm{~h}$ before measurements. The thermal stabilities of as-prepared samples were characterized by thermal gravimetric analysis (TGA) by utilizing a Q50 TA thermal analysis instrument from USA under nitrogen gas.

\section{Evaluation of photocatalytic activity}

The photocatalytic activities of the obtained samples were evaluated by degradation of Rhodamine B under visible light irradiation. $15 \mathrm{mg}$ of the photocatalyst was dispersed in a quartz glass tube which contained $30 \mathrm{~mL} \mathrm{RhB}$ aqueous solution with a concentration of $10 \mathrm{mg} \mathrm{L^{-1 }}$. Visible light irradiation was provided by a $400 \mathrm{~W}$ metal halide lamp and the sodium nitrite solution (1 M) was used to cut off UV light below $400 \mathrm{~nm}$. During irradiation, at selected time intervals, $5 \mathrm{~mL}$ of the suspension was taken out and centrifuged at $8000 \mathrm{rpm}$ for $5 \mathrm{~min}$ to remove the photocatalyst particles from the solution. The sampled liquid is back to reaction system after each absorbance test, so that the solution in the photo reactor basically remains unchanged. The temporal change of the concentration of RhB was recorded by monitoring the peak value of a maximum absorption of RhB solution by using a TU-1900 UV-vis spectrophotometer. The degradation rate $(\%)$ can be calculated according to $\eta(\%)=\left[\left(C_{0}-C\right) / C_{0}\right] \times 100 \%=\left[\left(A_{0}-A\right) / A_{0}\right] \times$ $100 \%$, where $C_{0}$ and $C$ respectively are the concentration of RhB solution at the initial moment and $t$ moment, and $A_{0}$ and $A$ respectively represent the corresponding absorbance values.

\section{Results and discussion}

\section{Yield comparison of samples}

The yields of all of samples are listed in Table 1. By comparison of $\mathrm{S}_{600-4}, \mathrm{~S}_{600-6}, \mathrm{~S}_{600-8}, \mathrm{~S}_{600-10}$ samples, one can find that the yields of samples are decreased with the prolonging of calcination time. In addition, the yields are also decreased with the increasing of calcination temperature by comparison of $\mathrm{S}_{500-10}$, $\mathrm{S}_{550-10}, \mathrm{~S}_{600-10}, \mathrm{~S}_{650-10}$ and $\mathrm{S}_{700-10}$ samples. This is ascribed to

Table 1 Yield comparison of all samples

\begin{tabular}{llllll}
\hline Sample & $\mathrm{S}_{600-4}$ & $\mathrm{~S}_{600-6}$ & $\mathrm{~S}_{600-8}$ & $\mathrm{~S}_{600-10}$ & $\mathrm{~S}_{500-10}$ \\
Yield, \% & 52 & 49 & 45 & 40 & 68 \\
Sample & $\mathrm{S}_{550-10}$ & $\mathrm{~S}_{650-10}$ & $\mathrm{~S}_{700-10}$ & $\mathrm{~S}^{\prime}{ }_{650-10}$ & \\
Yield, \% & 56 & 25 & 0 & 0 &
\end{tabular}

destruction of chemical bond between two tri-s-triazine units in polymeric $\mathrm{g}-\mathrm{C}_{3} \mathrm{~N}_{4}$ at higher temperature, resulting in production of nitrogen and cyano fragments. ${ }^{42}$ The decreased yields can also be confirmed by subsequent TGA analysis. Typically, the $\mathrm{g}-\mathrm{C}_{3} \mathrm{~N}_{4}$ samples $\mathrm{S}_{600-10}$ and $\mathrm{S}_{650-10}$ obtained at $600{ }^{\circ} \mathrm{C}$ and $650{ }^{\circ} \mathrm{C}$ for $10 \mathrm{~h}$ have the yield of $40 \%$ and $25 \%$, respectively. In addition, the yields of $\mathrm{S}_{700-10}$ and $\mathrm{S}_{650-10}$ samples are both zero, although in a tightly sealed alumina crucible system, no any product is obtained at $700{ }^{\circ} \mathrm{C}$. Similarly, no any product is obtained in a semi-sealed alumina crucible system, although at $650{ }^{\circ} \mathrm{C}$.

\section{Morphology and microstructure}

Fig. 2 shows the photograph of all samples with the same mass of $20 \mathrm{mg}$, one can clearly see that the volumes of $\mathrm{S}_{600-4}, \mathrm{~S}_{600-6}$, $\mathrm{S}_{600-8}$ and $\mathrm{S}_{600-10}$ samples gradually increase with the prolonging of the calcination time, and those of $\mathrm{S}_{500-10}, \mathrm{~S}_{550-10}, \mathrm{~S}_{600-10}$ and $\mathrm{S}_{650-10}$ samples also present a tendency to gradually increase with the increasing of the calcination temperature. The volumes of $\mathrm{S}_{600-10}$ and $\mathrm{S}_{650-10}$ samples are larger than those of other samples, indicating that the $\mathrm{g}-\mathrm{C}_{3} \mathrm{~N}_{4}$ samples with a loosely stacked state can be obtained at $600{ }^{\circ} \mathrm{C}$ and $650{ }^{\circ} \mathrm{C}$ for $10 \mathrm{~h}$ of the calcination time. Clearly, the volume of $\mathrm{S}_{650-10}$ sample is largest, presenting the loosest stacked state.

The influences of the calcination time and the calcination temperature on the morphology of samples can be further investigated by SEM. SEM images of $\mathrm{S}_{600-4}, \mathrm{~S}_{600-6}, \mathrm{~S}_{600-8}$ and $\mathrm{S}_{600-}$ ${ }_{10}$ samples calcined at $600{ }^{\circ} \mathrm{C}$ for different calcination time are shown in Fig. 3. From Fig. 3a and b, one can see that the two samples exhibit the obvious irregular blocky structure. The surfaces of the blocks are smooth, and the loose inner structure can be observed from some broken blocks. Fig. 3c and d show SEM images with different magnifications of $\mathrm{S}_{600-8}$ sample. From Fig. 3c, one can see that the irregular blocks break down, and the inner layers wrapped by the shell get dispersed. The high magnification SEM image of loose inner layers is shown in Fig. 3d, lots of curled sheet structures are observed. SEM images with different magnifications of $\mathrm{S}_{600-10}$ sample are shown in Fig. 3e and $\mathrm{f}$. It can be clearly observed, $\mathrm{S}_{600-10}$ sample presents curled nanosheet structure. In brief, at the fixed calcination temperature of $600{ }^{\circ} \mathrm{C}$, when the calcination time is extended

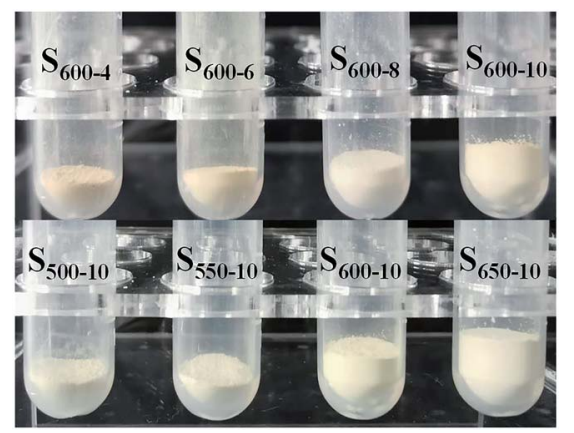

Fig. 2 Photograph of volume comparison of samples with the same mass (20 mg). 


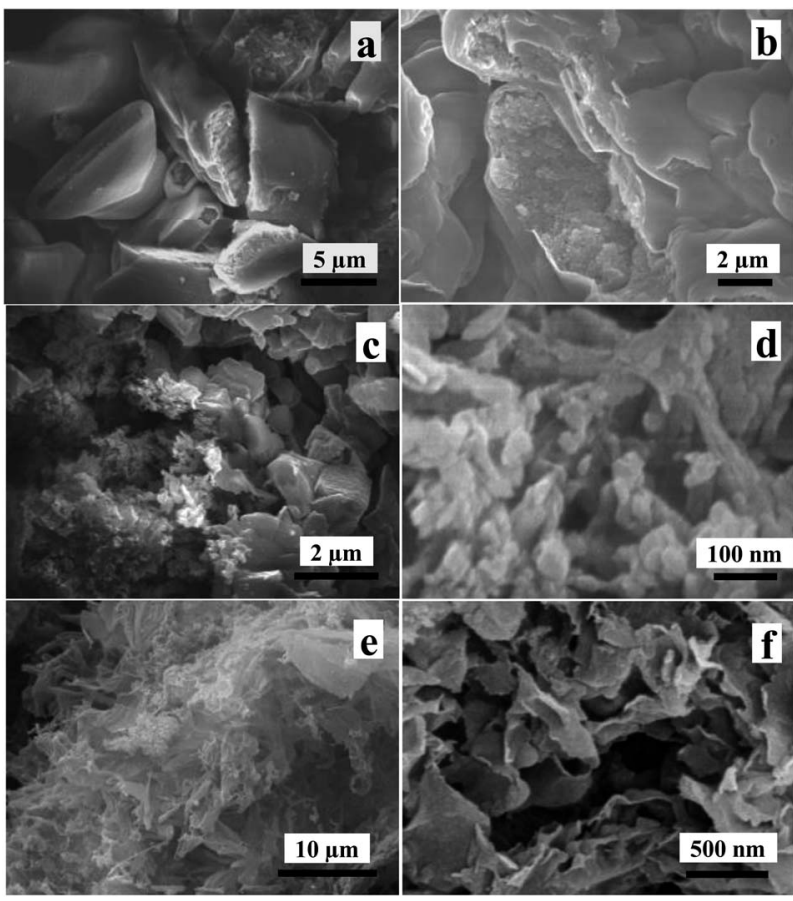

Fig. 3 SEM images of $\mathrm{S}_{600-4}$ (a), $\mathrm{S}_{600-6}$ (b), $\mathrm{S}_{600-8}$ (c and d) and $\mathrm{S}_{600-10}$ (e) and (f) samples.

from $4 \mathrm{~h}$ to $10 \mathrm{~h}$, the samples change from bulk structure to loose nanosheet structure with a thickness of several nanometers and a width of several microns. The nanosheet structure is curled because of its high surface energy.

Fig. 4 shows that SEM images of $\mathrm{S}_{500-10}, \mathrm{~S}_{550-10}, \mathrm{~S}_{600-10}$ and $\mathrm{S}_{650-10}$ samples calcined at different calcination temperature for $10 \mathrm{~h}$ of calcination time. From Fig. $4 \mathrm{a}$, one can see that $\mathrm{S}_{500-10}$ sample exhibits the obvious blocky structure with lateral scale of about $40 \mu \mathrm{m}$ and thickness of about $2-4 \mu \mathrm{m}$. Partial broken structures are observed. SEM image of $\mathrm{S}_{550-10}$ sample in Fig. $4 \mathrm{~b}$ exhibits the layered structure, and the lateral scale and the thickness obviously decrease to about $20 \mu \mathrm{m}$ and $1 \mu \mathrm{m}$, compared with the $S_{500-10}$ sample. In addition, some curled nanosheets are observed. The high magnification SEM image in Fig. 4c further confirms that the multi-layered structure is formed, and the surface has been exfoliated into curved and fragile nanosheets. Fig. $4 \mathrm{~d}$ and e show SEM images of $\mathrm{S}_{600-10}$ sample with different magnification, it can be seen that the multi-layered sheets are almost completely split into ultrathin nanosheets, which show curled state with wrinkles and rolling edges. From Fig. 4e, it can be observed that the lateral scale of nanosheet is several micrometers and the thickness is about several nanometers. Fig. $4 \mathrm{f}$ and $\mathrm{g}$ show SEM images of $\mathrm{S}_{650-10}$ sample with different magnification. It is clear that lots of fragmented structures are observed and the average size of nanosheets is significantly reduced. Fig. $4 \mathrm{~g}$ shows that the lateral size of most nanosheets is about 100-200 nm. By comparison of all SEM images, one can conclude that $\mathrm{S}_{650-10}$ sample has the smallest size, and shows the loosest stack state.

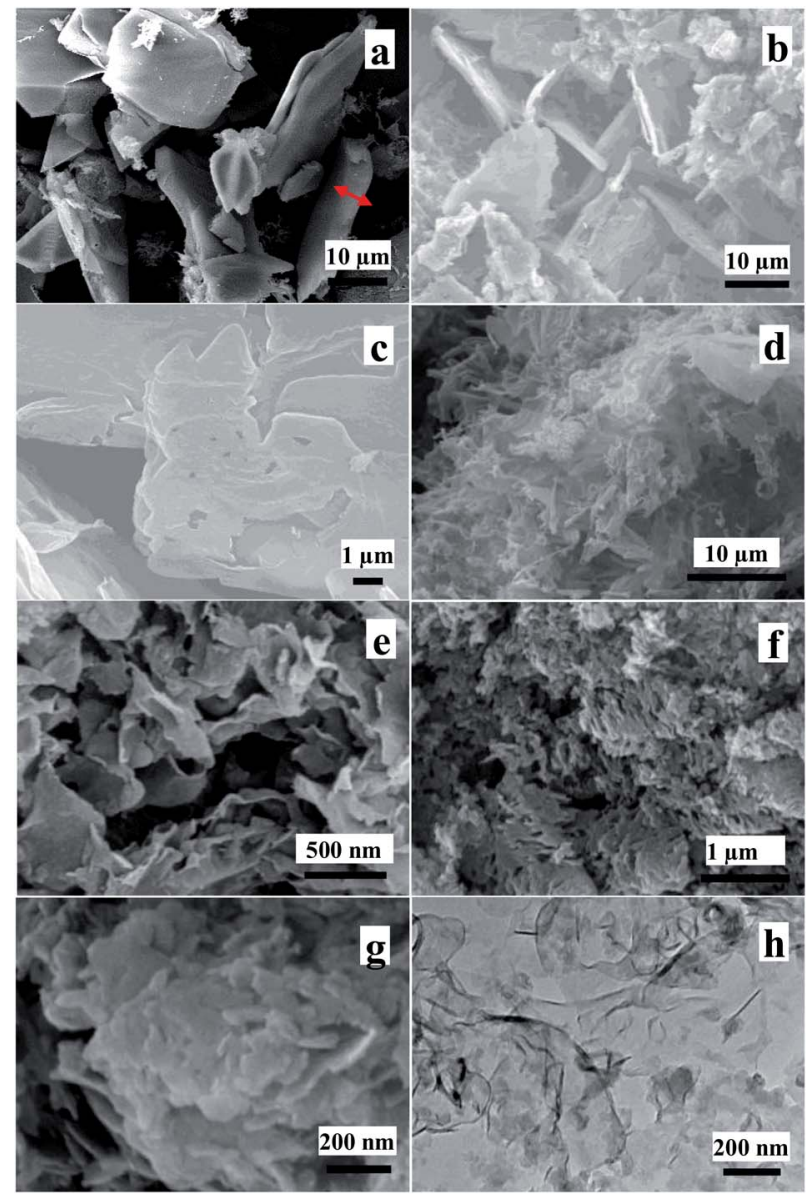

Fig. 4 SEM images of $S_{500-10}(a), S_{550-10}(b$ and $c), S_{600-10}(d$ and e) and $\mathrm{S}_{650-10}$ (f and g) samples and TEM image of $\mathrm{S}_{650-10}(\mathrm{~h})$ sample.

In order to further demonstrate the microstructure of the obtained nanosheets, TEM image of $\mathrm{S}_{650-10}$ sample is shown in Fig. $4 \mathrm{~h}$. TEM image shows that as-prepared g- $\mathrm{C}_{4} \mathrm{~N}_{4}$ has nearly transparent feature, indicating that the $\mathrm{g}^{-} \mathrm{C}_{3} \mathrm{~N}_{4}$ sample with ultrathin thickness is obtained. Moreover, the curved edges of nanosheets are observed, which is consistent with the analytical results by SEM observation.

AFM image and corresponding height profile in Fig. 5 further confirm the ultrathin structure feature of $\mathrm{g}-\mathrm{C}_{3} \mathrm{~N}_{4}$ nanosheet, and the average thickness is about $2 \mathrm{~nm}$ in height, indicating that the multi-layered bulks are successfully exfoliated into ultrathin nanosheets. In addition, the nanosheets with a thickness of more than $3 \mathrm{~nm}$ are observed, which is presumably derived from the folds and wrinkles on the nanosheets.

\section{Crystal structure and chemical compositions}

The XRD patterns of $S_{500-10}, S_{550-10}, S_{600-10}$ and $S_{650-10}$ samples obtained from different calcination temperature are shown in Fig. 6a. The XRD patterns of all of samples exhibit similar characteristic diffraction peaks at around $13.0^{\circ}$ and $27.6^{\circ}$, which are consistent with the typical graphite-like hexagonal phase of $g-\mathrm{C}_{3} \mathrm{~N}_{4}$ (JCPDS 87-1526). The low-angle diffraction peak 

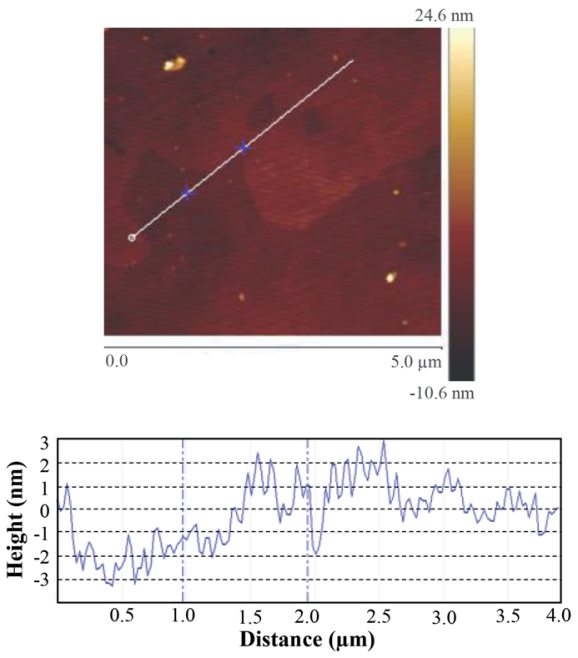

Fig. 5 AFM image of $\mathrm{S}_{650-10}$ and the corresponding height profile of randomly chosen section.
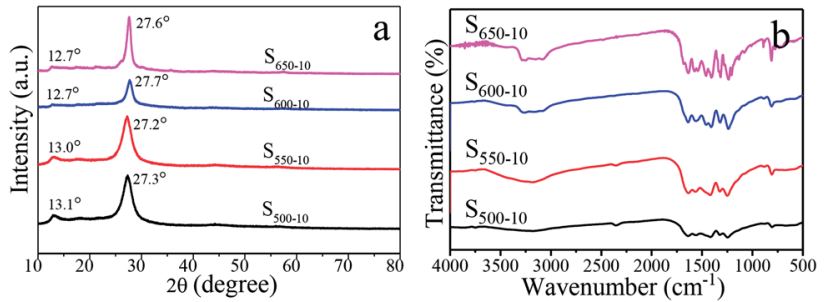

Fig. 6 XRD patterns (a) and FT-IR spectra (b) of $S_{500-10}, S_{550-10}, S_{600-10}$ and $\mathrm{S}_{650-10}$ samples.

around $13.0^{\circ}$ assigned to (100) plane corresponds to the inplane structural stacking of tri-s-triazine units, the typical dominant peak around $27.6^{\circ}$ assigned to (002) plane is attributed to the inter-layer stacking of the conjugated aromatic systems, corresponding to the interplanar distances of $0.326 \mathrm{~nm}$ and $0.675 \mathrm{~nm}$, respectively. ${ }^{43,44}$ In addition, one can see that the diffraction angle $2 \theta$ of (002) peak increases from $27.3^{\circ}$ and $27.2^{\circ}$ for $S_{500-10}$ and $S_{550-10}$ samples to $27.7^{\circ}$ and $27.6^{\circ}$ for $\mathrm{S}_{600-10}$ and $\mathrm{S}_{650-10}$ samples when the calcination temperature increases from $500{ }^{\circ} \mathrm{C}$ to $650^{\circ} \mathrm{C}$. This result may be attributed to the stack of $\mathrm{g}-\mathrm{C}_{3} \mathrm{~N}_{4}$ becomes denser and more ordered at higher calcination temperature. ${ }^{31}$ More interestingly, the intensity of diffraction peak decreases when the calcination temperature increases from $500{ }^{\circ} \mathrm{C}$ to $600^{\circ} \mathrm{C}$, while the intensity significantly increases when the temperature increases to $650{ }^{\circ} \mathrm{C}$. The decrease in peak intensity of $\mathrm{S}_{600-10}$ sample may be interpreted as the more structural defects in sample. The increase in peak intensity of $S_{650-10}$ sample could be attributed to the reduced number of structural defects and the enhanced crystallinity due to the formation of perfect tri-s-triazine (melem) structure units when the calcination temperature increases to $650{ }^{\circ} \mathrm{C} .{ }^{31,37}$

The surface functional groups of the obtained $\mathrm{g}-\mathrm{C}_{3} \mathrm{~N}_{4}$ samples are monitored by FT-IR spectroscopy, and the spectra of three samples are shown in Fig. 6b. The strong absorption bands further reveal a typical graphitic carbon nitride molecular structure feature. The broad absorption band in the region from $3000 \mathrm{~cm}^{-1}$ to $3500 \mathrm{~cm}^{-1}$ originates from the uncondensed terminal amino groups $\left(-\mathrm{NH}_{2}\right.$ or $\left.=\mathrm{NH}\right) \cdot{ }^{28}$ Several strong bands in the $1230-1650 \mathrm{~cm}^{-1}$ region are attributed to the stretching vibrations of $\mathrm{C}-\mathrm{N}$ and $\mathrm{C}=\mathrm{N}$ from aromatic heterocycles. ${ }^{28}$ The sharp peak at around $805 \mathrm{~cm}^{-1}$ is assigned to the bending vibration of triazine rings. ${ }^{28}$ By comparison, it can be seen that the absorption peaks of $\mathrm{S}_{650-10}$ became sharper than those of the other samples, which may be interpreted as the rearrangement of the $\mathrm{CN}$ units and the more ordered packing of the polymeric tri-s-triazine (melem) units at higher calcination temperature. $^{31,37}$

The obtained $\mathrm{S}_{650-10}$ nanosheet as a representative example is further studied by XPS to reveal its chemical composition and oxidation state, as shown in Fig. 7a-c. It is clear that C, $\mathrm{N}$ and $\mathrm{O}$ elements are detected in the XPS survey spectra in Fig. 7a. The $\mathrm{O}_{1 \mathrm{~s}}$ peak may be derived from the surface absorbed oxygen species. The backbone $\mathrm{C}$ and $\mathrm{N}$ elements of $\mathrm{S}_{650-10}$ are further investigated by the high resolution spectra. For $\mathrm{C}_{1 \mathrm{~s}}$ spectra in Fig. $7 \mathrm{~b}$, a predominant peak at $287.9 \mathrm{eV}$ is observed in nanosheet, which is assigned to the $\mathrm{N}=\mathrm{C}-(\mathrm{N})_{2}$ bonds in the $\mathrm{g}-\mathrm{C}_{3} \mathrm{~N}_{4}$ lattice. ${ }^{6}$ The peak at $284.6 \mathrm{eV}$ is assigned to $\mathrm{C}-\mathrm{C}$ bonds, which is related to adventitious carbon species. ${ }^{45}$ The high resolution $\mathrm{N}_{1 \mathrm{~s}}$ spectra in Fig. 7c show four different peaks at 398.5, 399.7, 400.9, $404.0 \mathrm{eV}$, which can be ascribed to the $\mathrm{sp}^{2}$-hybridized nitrogen in triazine rings $(\mathrm{C}=\mathrm{N}-\mathrm{C})$, the tertiary nitrogen groups $\left(\mathrm{N}-(\mathrm{C})_{3}\right)$, the free amino groups $\left((\mathrm{C})_{2} \mathrm{~N}-\mathrm{H}\right.$ or $\left.\mathrm{C}-\mathrm{NH}_{2}\right)$ and $\pi$ excitations, respectively. ${ }^{6}$

\section{BET surface areas and pore size distribution}

In order to characterize the specific surface areas and porosity of $\mathrm{g}^{-} \mathrm{C}_{3} \mathrm{~N}_{4}$ samples obtained under different calcination temperature, the nitrogen adsorption-desorption isotherms and Barrett-Joyner-Halenda (BJH) pore size distributions (PSD) are shown in Fig. 8. The illustration is a magnification when the
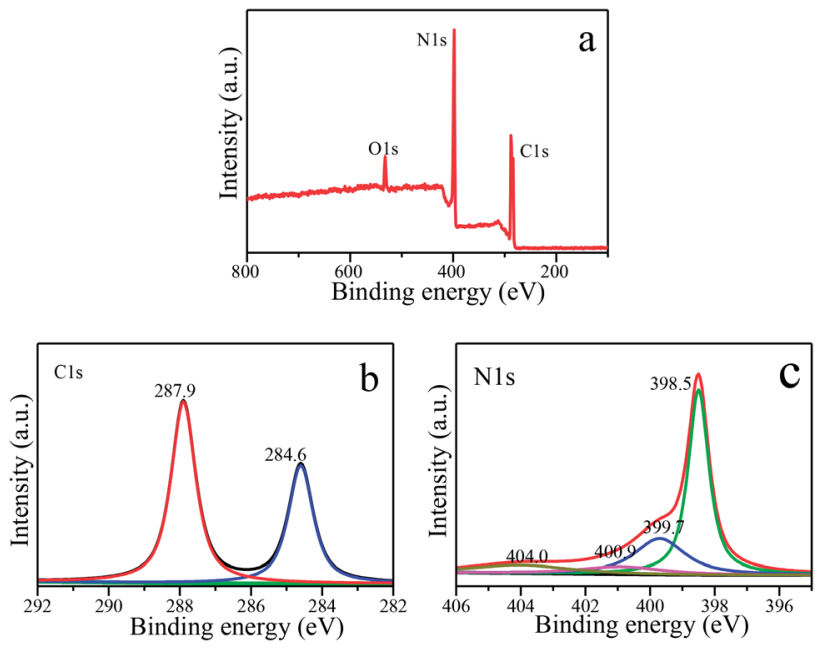

Fig. 7 XPS spectra of $S_{650-10}$ sample. (a) XPS survey. (b) $C_{1 s}$ spectra. (c) $\mathrm{N}_{1 \mathrm{~s}}$ spectra. 

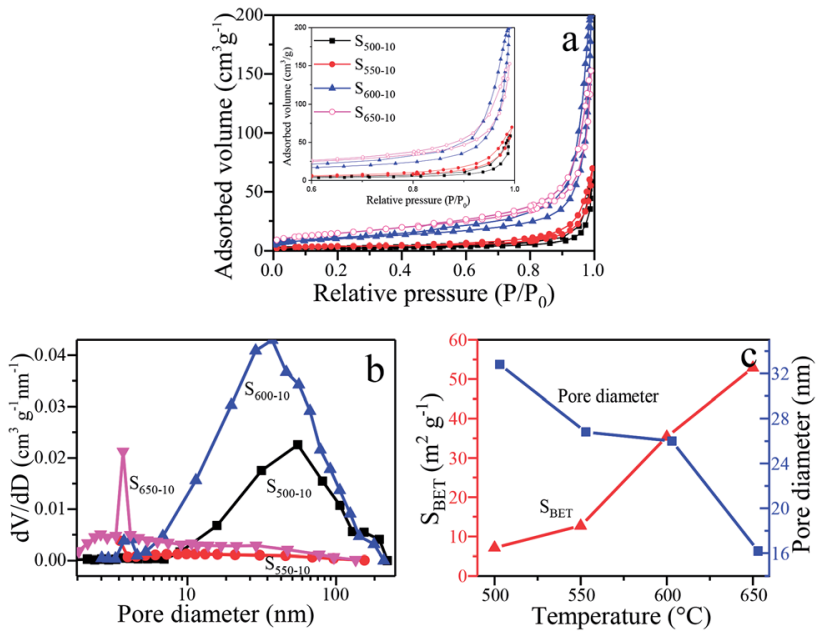

Fig. 8 (a) $\mathrm{N}_{2}$ adsorption-desorption isotherms, the inset is a magnification when the relative pressure is $0.6-1.0$. (b) The corresponding PSD curves and (c) the correlation between $\mathrm{S}_{\mathrm{BET}}, \mathrm{APD}$ and temperature of $\mathrm{S}_{500-10}, \mathrm{~S}_{550-10}, \mathrm{~S}_{600-10}, \mathrm{~S}_{650-10}$ samples.

relative pressure is 0.6-1.0. From Fig. 8a, the type IV (BDDT classification) shape of adsorption-desorption isotherms with an H3-type hysteresis loops for all the samples can be observed, suggesting the presence of slit-shaped mesopores derived from the aggregates of sheet-like particles. ${ }^{31,37}$ The correlation of the BET surface areas, the BJH desorption average pore diameter and the calcination temperature for $\mathrm{S}_{500-10}, \mathrm{~S}_{550-10}, \mathrm{~S}_{600-10}, \mathrm{~S}_{650-10}$ samples is indicated in Fig. 8c. It can be clearly seen that the surface areas of the samples are remarkably increased and average pore diameter decreased with the increase of calcination temperature. The BET surface areas $\left(\mathrm{S}_{\mathrm{BET}}\right)$ of $\mathrm{S}_{500-10}, \mathrm{~S}_{550-10}$, $\mathrm{S}_{600-10}, \mathrm{~S}_{650-10}$ samples are respectively $7.1 \mathrm{~m}^{2} \mathrm{~g}^{-1}, 12.7 \mathrm{~m}^{2} \mathrm{~g}^{-1}$, $35.4 \mathrm{~m}^{2} \mathrm{~g}^{-1}$ and $52.9 \mathrm{~m}^{2} \mathrm{~g}^{-1}$, and the BJH desorption average pore diameter (APD) are respectively 33, 27, 26, $16 \mathrm{~nm}$ (Table 2). From Fig. 8b, the PSD of $\mathrm{S}_{500-10}$ sample ranges from $10 \mathrm{~nm}$ to $110 \mathrm{~nm}$, the larger mesopores are related to the pores formed between packed layers. Most probable aperture is $55 \mathrm{~nm}$. With regard to $S_{550-10}$ sample, the pore size distribution is from $7 \mathrm{~nm}$ to $30 \mathrm{~nm}$, and most probable aperture is $10 \mathrm{~nm}$. In addition, small mesopores with the diameter less than $3.5 \mathrm{~nm}$ are observed. The pore area is obviously reduced compared with $\mathrm{S}_{500-10}$ sample, indicating that the multilayer structure has been exfoliated to monolayer or a few layers structure. This is consistent with SEM images of $\mathrm{S}_{500-10}$ and $\mathrm{S}_{550-10}$ samples (Fig. $4 \mathrm{a}$ and b). For $\mathrm{S}_{600-10}$ sample, the pore area is obviously increased compared with other samples, the PSD is from $10 \mathrm{~nm}$ to $110 \mathrm{~nm}$, and most probable aperture is $37 \mathrm{~nm}$. The larger mesopores are related to the pores formed from curled sheets

Table $2 S_{\mathrm{BET}}$ and APD of samples

\begin{tabular}{lllll}
\hline Sample & $\mathrm{S}_{500-10}$ & $\mathrm{~S}_{550-10}$ & $\mathrm{~S}_{600-10}$ & $\mathrm{~S}_{650-10}$ \\
\hline$S_{\text {BET }}\left(\mathrm{m}^{2} \mathrm{~g}^{-1}\right)$ & 7.1 & 12.7 & 35.4 & 52.9 \\
APD $(\mathrm{nm})$ & 33 & 27 & 26 & 16
\end{tabular}

(Fig. 4d). For $\mathrm{S}_{650-10}$ sample, the PSD curve is quite broad (from $1 \mathrm{~nm}$ to $100 \mathrm{~nm}$ ) with small mesopores and large mesopores, and most probable aperture is $4 \mathrm{~nm}$. The proportion of small mesopores is more larger than large mesopores, and the smaller mesopores may reflect porosity within the nanoscale sheets. This is because that $\mathrm{S}_{650-10}$ sample presents small and thin nanosheet structure and has best dispersion due to the higher calcination temperature of $650{ }^{\circ} \mathrm{C}$. This has been confirmed in SEM images in Fig. $4 \mathrm{f}$ and $\mathrm{g}$. The analysis results indicate that the specific surface area of samples increase with the increase of the calcination temperature, which can be attributed to the decreased size and thickness of $\mathrm{g}-\mathrm{C}_{3} \mathrm{~N}_{4}$ samples. Generally, the $\mathrm{g}-\mathrm{C}_{3} \mathrm{~N}_{4}$ nanosheets with mesoporosity have enlarged specific surface area. The enlarged specific surface area could improve mass transfer ability and provide larger number of active redox reaction sites, and further efficiently enhance photocatalytic activity. ${ }^{38}$

\section{Optical property and band gap}

The effects of the calcination temperature on the optical property are investigated by UV-vis DRS spectra and PL spectra. The photoabsorption abilities of $S_{500-10}, S_{550-10}, S_{600-10}$ and $S_{650-10}$ samples are characterized with UV-vis absorption spectrum, as shown in Fig. 9a. Obviously, all the g- $\mathrm{C}_{3} \mathrm{~N}_{4}$ samples exhibit an absorption edge in the visible light region. It is worth noting that $\mathrm{S}_{550-10}, \mathrm{~S}_{600-10}$ and $\mathrm{S}_{650-10}$ samples show clear hypsochromic shifts on the absorption edge compared with $S_{500-10}$ sample. In addition, the UV-visible absorption spectra of $S_{650-10}$ sample shows a significant enhancement of the absorption in the visible region compared with the other samples. Besides, the absorption in the UV region is also enhanced. The calculated band gap energy values $\left(E_{\mathrm{g}}\right)$ of $\mathrm{g}-\mathrm{C}_{3} \mathrm{~N}_{4}$ samples on the basis of the UV-vis DRS data are indicated in Fig. 9b, it can be seen that band gap energy is increased from $2.58 \mathrm{eV}$ to $2.84 \mathrm{eV}$ when the calcination temperature increases from $500{ }^{\circ} \mathrm{C}$ to $600{ }^{\circ} \mathrm{C}$, then is slightly decreased from $2.84 \mathrm{eV}$ to $2.73 \mathrm{eV}$ when the calcination temperature increases from $600{ }^{\circ} \mathrm{C}$ to $650{ }^{\circ} \mathrm{C}$.

The hypsochromic shift on the absorption edge of the UVvisible absorption spectra can be ascribed to the quantum confinement effect induced by nanosized particles. As is shown in Fig. 4, the higher temperature makes the thickness and size of $\mathrm{g}-\mathrm{C}_{3} \mathrm{~N}_{4}$ layers evidently decreased, resulting in the evident quantum confinement effect. Because of the quantum confinement effect, the energy levels on the conduction band
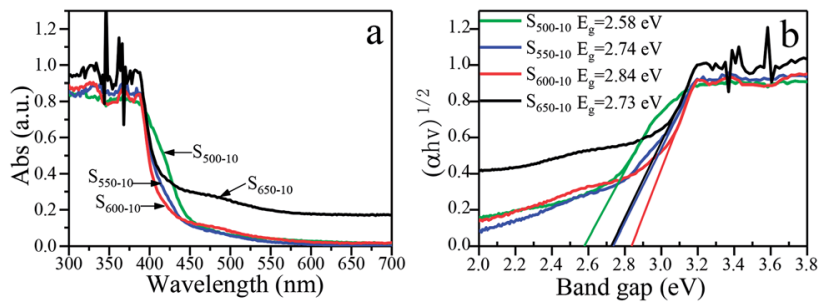

Fig. 9 (a) UV-vis DRS spectra and (b) plots of $(\alpha h \nu)^{1 / 2} v s$. photon energy of $\mathrm{S}_{500-10}, \mathrm{~S}_{550-10}, \mathrm{~S}_{600-10}$ and $\mathrm{S}_{650-10}$ samples. 
and valence band become separated levels, the energy gap gets widen, the valence band potential become more positive and the conduction band potential become more negative, which increases the redox ability of photogenerated holes and electrons. This will further enhance the photocatalytic activity of the samples.

For $\mathrm{S}_{650-10}$ sample, the slight decrease of band gap energy can be explained by the unique effect of the calcination temperature on the molecular structure and crystal structure of the polymeric $\mathrm{g}-\mathrm{C}_{3} \mathrm{~N}_{4}$. At the calcination temperature of $650{ }^{\circ} \mathrm{C}$, the obtained $\mathrm{g}-\mathrm{C}_{3} \mathrm{~N}_{4}$ nanosheets should be mainly constructed from tri-s-triazine (melem) structure units, the structure units show enhanced structural connections, which would result in the decrease of band gap of $\mathrm{g}-\mathrm{C}_{3} \mathrm{~N}_{4} \cdot{ }^{37}$ In addition, the enhancement of the absorption in the visible region and $\mathrm{UV}$ region for $\mathrm{S}_{650-10}$ sample may be ascribed to the larger specific surface area, which can absorb more light energy to generate more electron hole pairs. Photogenerated carriers can easily migrate from the interior of particles to the surface through simple diffusion, and take part in the redox reaction with electron donor or acceptor. The less time the electrons diffuse from the interior to the surface, the higher the separation efficiency of the photogenerated charge is. This higher separation efficiency could improve the probability of their involvement in photocatalytic reaction before recombination and enhance the photocatalytic activity.

Commonly, the separation and recombination of the photogenerated charge-carriers are monitored by photoluminescence (PL) spectra. The PL spectra of $S_{500-10}, S_{550-10}, S_{600-}$ 10 and $S_{650-10}$ samples with an excitation wavelength of $328 \mathrm{~nm}$ are shown in Fig. 10. All of samples exhibit the obvious PL emission peaks centered at about $450-470 \mathrm{~nm}$, indicating that the $\pi$-conjugated system of $\mathrm{C}_{3} \mathrm{~N}_{4}$ samples is constant under different calcination temperature. Interestingly, for $\mathrm{S}_{500-10}, \mathrm{~S}_{550-}$ ${ }_{10}$ and $S_{600-10}$ samples, a drastic quenching phenomenon of the PL peak intensity is observed with the increase of the calcination temperature, especially for $S_{600-10}$ sample, but PL peak intensity of $\mathrm{S}_{650-10}$ sample is remarkably enhanced. For $\mathrm{S}_{600-10}$ sample, the decline of PL intensity should be attributed to the more structural defects in the samples and decreased crystallinity. When the temperature is at $600{ }^{\circ} \mathrm{C}$, multi-layered sheetlike $\mathrm{g}-\mathrm{C}_{3} \mathrm{~N}_{4}$ sample are almost completely split into ultrathin nanosheets, the specific surface areas significantly increase, which may result in more defects and poor crystallinity. More structural defects in the samples could capture the electrons or

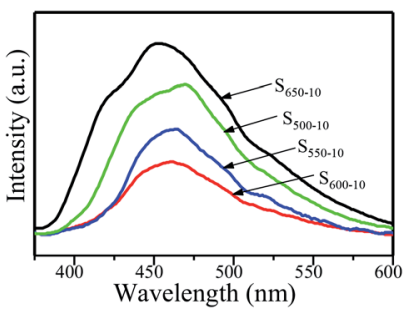

Fig. 10 Room-temperature PL spectra of $S_{500-10}, S_{550-10}, S_{600-10}$ and $\mathrm{S}_{650-10}$ samples under $328 \mathrm{~nm}$ excitation. holes and prevent the recombination probability of photogenerated electron-hole pairs and thus lead to the decline in PL intensity. ${ }^{31,37}$ For $\mathrm{S}_{650-10}$ sample, the enhanced PL intensity should be attributed to the improved crystal structure and the reduced number of structural defects. When the temperature increases to $650{ }^{\circ} \mathrm{C}$, the crystallinity of $\mathrm{S}_{650-10}$ sample is improved due to the formation of perfect tri-s-triazine (melem) structure units with enhanced structural connections, and the number of structural defects is reduced, the recombination probability of photogenerated electron-hole pairs is increased and thus the PL intensity is enhanced. ${ }^{31,37}$ Although the recombination probability of photogenerated electron-hole pairs is reduced, the transitions of electrons or holes to the defects belongs to harmful radiationless transitions, which is equivalent to reducing the effective utilization ratio of electrons or holes participating in the redox reactions of the organic pollutants. Therefore, both the PL intensity and photocatalytic activity of $\mathrm{S}_{650-10}$ sample are significantly enhanced by decreasing harmful radiationless transitions.

\section{Thermal stability}

The thermal stability of $\mathrm{g}-\mathrm{C}_{3} \mathrm{~N}_{4}$ sample $\left(\mathrm{S}_{650-10}\right)$ is characterized by TGA. The TGA curve of $\mathrm{g}-\mathrm{C}_{3} \mathrm{~N}_{4}$ is illustrated in Fig. 11. It can be seen that the TGA curve displays that its decomposition temperature begins at about $580{ }^{\circ} \mathrm{C}$, and the weight loss reaches $100 \%$ at about $700{ }^{\circ} \mathrm{C}^{46}$ This is ascribed to destruction of chemical bond between two tri-s-triazine units in polymeric $\mathrm{g}$ $\mathrm{C}_{3} \mathrm{~N}_{4}$ at high temperature, resulting in production of nitrogen and cyano fragments. ${ }^{42}$

\section{Formation mechanism}

A new layer exfoliation and splitting mechanism of the formation of the ultrathin nanosheet is proposed. In the present work, a certain mass of melamine powders are placed in an alumina crucible covered with its lid and tightly wrapped by aluminum foil, then the whole is put in a muffle furnace and heated to $650{ }^{\circ} \mathrm{C}$ at a heating rate of $1{ }^{\circ} \mathrm{C} \mathrm{min}^{-1}$, and kept for $10 \mathrm{~h}$ at $650{ }^{\circ} \mathrm{C}$. Schematic for the formation mechanism of $\mathrm{g}-\mathrm{C}_{3} \mathrm{~N}_{4}$ nanosheet from the melamine precursor is shown in Scheme 1a. When the temperature of system rises to above $250{ }^{\circ} \mathrm{C}$, melamine powders turn molten, and the melamine molecules begin to gather together and the molecular spacing become smaller. As temperature rises gradually, the intermolecular condensation reaction of melamine occurs, and small amounts of ammonia is generated. Melam and melem are main

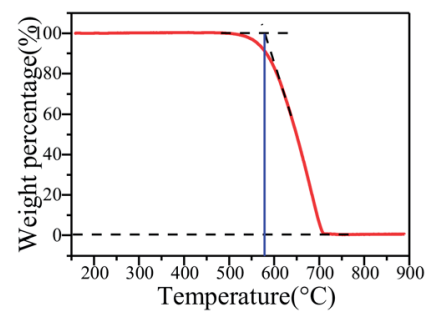

Fig. 11 TGA curve of $\mathrm{g}-\mathrm{C}_{3} \mathrm{~N}_{4}$ sample $\mathrm{S}_{650-10}$ 

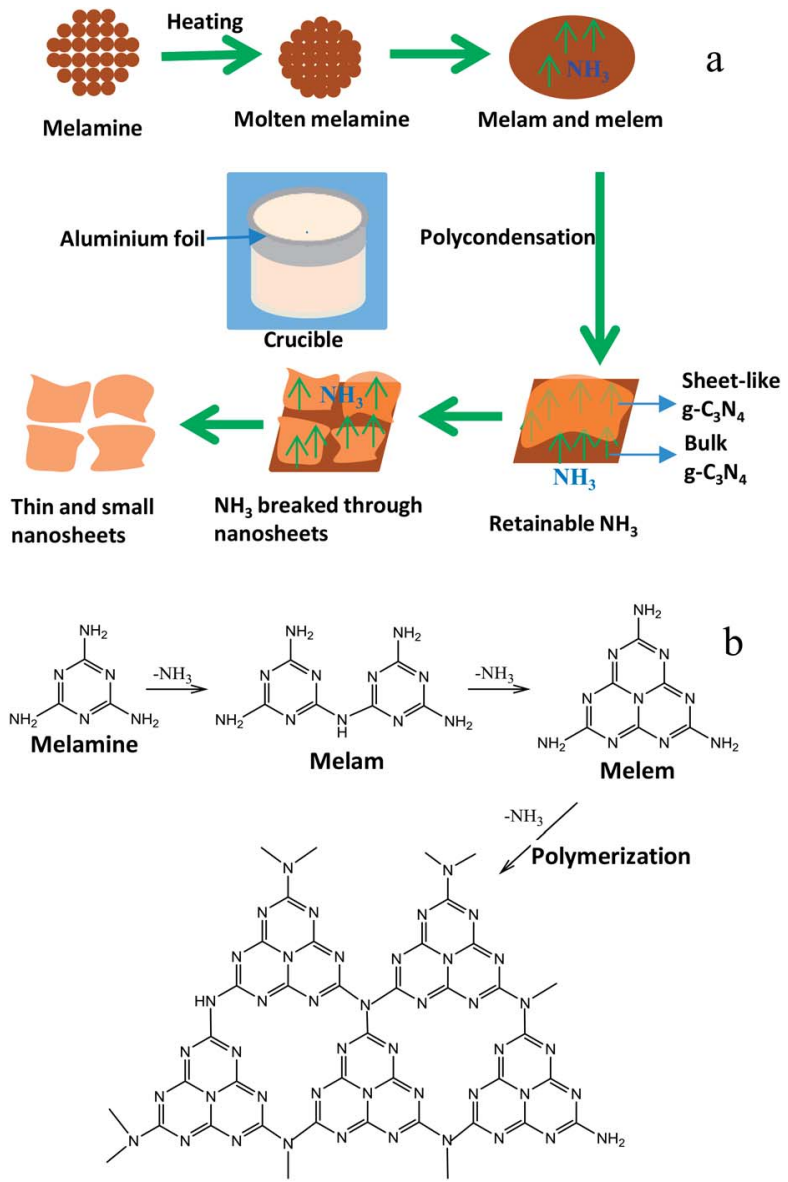

Scheme 1 Schematic for the formation (a) and the reaction paths (b) of $\mathrm{g}-\mathrm{C}_{3} \mathrm{~N}_{4}$ nanosheet from the melamine precursor.

condensation products at an initial stage. When the temperature increases to about $450{ }^{\circ} \mathrm{C}$, the thermal polycondensation reaction among melam, melem and melamine oligomer molecules begins to occur, and the tris-s-triazine structure begin to form preliminarily. At this time, the reaction rate is slow and the amount of ammonia released is less. In order to increase the reaction rate, the temperature is raised to $650{ }^{\circ} \mathrm{C}$. As is known to all, the polycondensation reaction is a step-by-step procedure, so that the formation of polymeric $\mathrm{g}-\mathrm{C}_{3} \mathrm{~N}_{4}$ needs a longer time to achieve a high degree of polycondensation. In view of this, the thermal treatment time is prolonged to $10 \mathrm{~h}$. The reaction system is maintained at $650{ }^{\circ} \mathrm{C}$ for $10 \mathrm{~h}$. With the increases of the degree of polycondensation, the generated ammonia is constantly increased. Due to the reaction system is tightly sealed, ammonia gas can keep circulating in system at a longer time. The circulating flow of large amounts of ammonia between layers of $\mathrm{g}-\mathrm{C}_{3} \mathrm{~N}_{4}$ favors not only the direct formation of ultrathin nanosheet structure bypass the transition state of bulk structure, but also the exfoliation of layered bulk structure into nanosheets. Finally, the favourable nanosheets are formed successfully, and some large size nanosheets are split into small size nanosheets. The result suggests that the thinner and looser nanoarchitectures of $\mathrm{g}-\mathrm{C}_{3} \mathrm{~N}_{4}$ can be obtained by prolonging the heat treatment time and increasing heat treatment temperature. This is consistent with the reported results in literatures. ${ }^{37,47,48}$ In conclusion, the retainable self-supporting ammonia, and the high calcination temperature and the prolonged calcination time co-contribute to the formation of ultrathin $\mathrm{g}-\mathrm{C}_{3} \mathrm{~N}_{4}$ nanosheets. Additionally, chemical reaction paths from the polycondensation of melamine precursor into g$\mathrm{C}_{3} \mathrm{~N}_{4}$ are shown in Scheme $1 \mathrm{~b} .^{49}$

\section{Photocatalytic activity and cycling stability}

The photocatalytic activities of all prepared g-C $\mathrm{N}_{3} \mathrm{~N}_{4}$ samples $\left(\mathrm{S}_{600-4}, \mathrm{~S}_{600-6}, \mathrm{~S}_{600-8}, \mathrm{~S}_{600-10}, \mathrm{~S}_{500-10}, \mathrm{~S}_{550-10}, \mathrm{~S}_{600-10}\right.$ and $\left.\mathrm{S}_{650-10}\right)$ are evaluated by degradating RhB aqueous solution under visible light irradiation. Two methods are used in photocatalytic experiments, one is that the catalyst samples and RhB solution mixture are magnetically stirred for 30 minutes in a dark before visible light irradiation for pre-adsorption, the other is that the
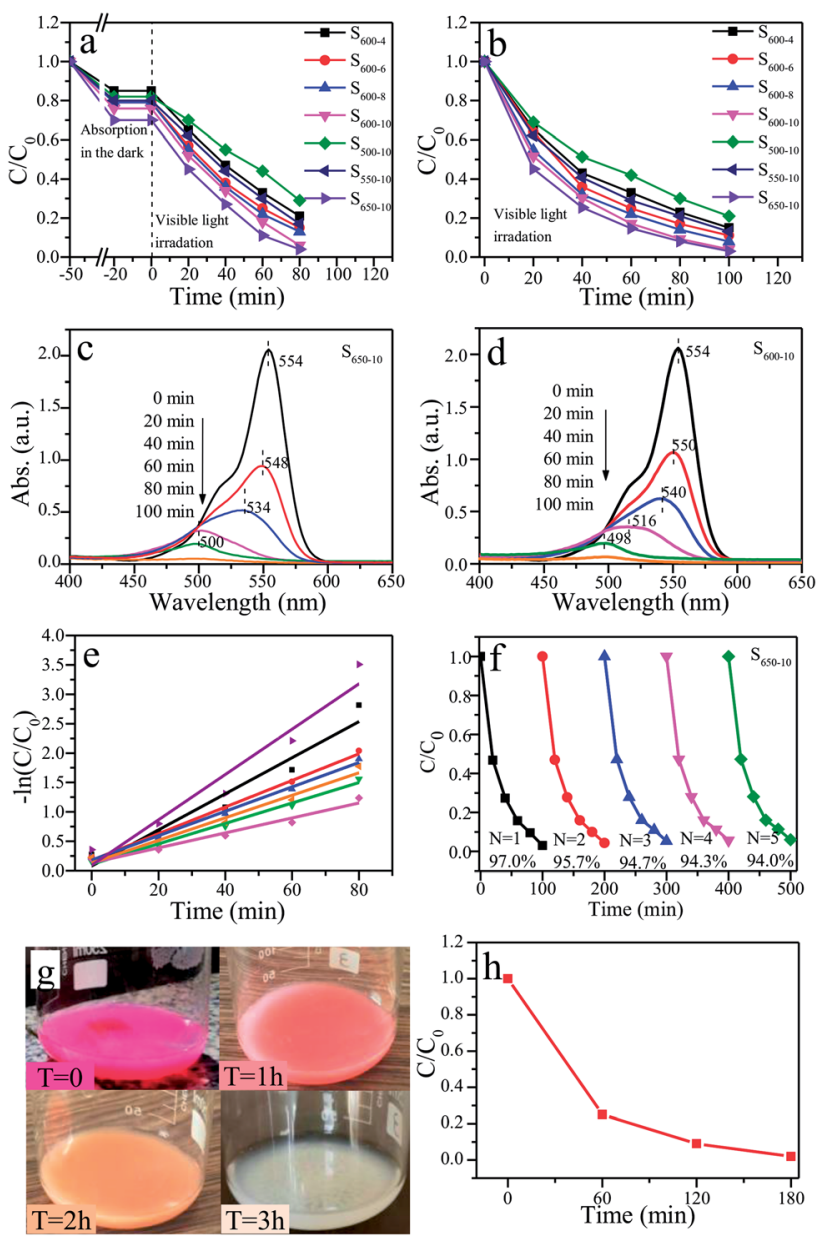

Fig. 12 The time-dependent curves of RhB concentration change under visible light irradiation $(\lambda>400 \mathrm{~nm})$ ((a) pre-absorption, (b) without pre-absorption). The temporal absorption spectra of $\mathrm{RhB}$ in the presence of $\mathrm{S}_{650-10}$ (c) and $\mathrm{S}_{600-10}$ (d) samples. (e) Linear transform $-\ln \left(\mathrm{C} / \mathrm{C}_{0}\right)$ of the kinetic curves of RhB degradation. (f) Photocatalytic reaction cycles of $\mathrm{S}_{650-10}$ sample. $(\mathrm{g})$ The color change pictures and (h) concentration change curve of RhB solution over $\mathrm{S}_{650-10}$ sample with time under natural sunlight. 
mixture are directly used in photocatalytic experiments without pre-adsorption. Fig. 12a and b show the time-dependent curves of RhB concentration change in two cases. It can be seen from Fig. 12a, after being stirred for $30 \mathrm{~min}$ in the dark, the concentrations of RhB solutions decreased by $15 \%-30 \%$, which indicating that the prepared samples have strong adsorption capacity on RhB. At this time, adsorption-desorption equilibrium is achieved in the mixed system. Under visible-light irradiation, the concentrations of RhB solutions in the presence of $\mathrm{g}-\mathrm{C}_{3} \mathrm{~N}_{4}$ samples show notable downward trends. This indicates that all prepared samples have good photocatalytic activities over the degradation of RhB. By comparison of the concentration change curves of RhB in the presence of $\mathrm{S}_{600-4}, \mathrm{~S}_{600-6}, \mathrm{~S}_{600-8}$ and $S_{600-10}$ samples, one can see that $S_{600-10}$ sample presents the highest photocatalytic activity. The corresponding degradation rate of $\mathrm{RhB}$ reaches $94 \%$ after 80 min irradiation. This indicates that the photocatalytic activities of samples will be improved with the prolonging of the calcination time when the calcination temperature is constant. Compared with $\mathrm{S}_{500-10}, \mathrm{~S}_{550-10}$ and $\mathrm{S}_{600-10}$ samples, $\mathrm{S}_{650-10}$ sample show the highest photocatalytic activity, and the degradation rate of $\mathrm{RhB}$ is $96 \%$. This implies that the photocatalytic activities of samples will be enhanced with the increase of the calcination temperature when the calcination time is constant. Moreover, among all the samples, $\mathrm{S}_{650-10}$ sample shows highest photocatalytic degradation efficiency over RhB. From Fig. 12b, it can be seen that the concentration change rate of $\mathrm{RhB}$ during the first $20 \mathrm{~min}$ visible-light irradiation are the largest. With the increase of irradiation time, the decline rates of $\mathrm{RhB}$ concentration slow down gradually. The primary reason is that, the concentration of RhB without pre-absorption are greater in the early stage of irradiation, and strong adsorption and photocatalysis proceed simultaneously so that the degradation rate of $\mathrm{RhB}$ is faster. Obviously, $\mathrm{S}_{600-10}$ and $\mathrm{S}_{650-10}$ samples show highest photocatalytic activities over RhB, which is consistent with the results from Fig. 12a. The corresponding degradation rate are respectively $96 \%$ and $97 \%$ after $100 \mathrm{~min}$ irradiation. The photocatalytic activity of $S_{650-10}$ sample is better than that of $S_{600-10}$ sample. This is because that $\mathrm{S}_{650-10}$ sample has stronger adsorption capacity, which is related to the larger specific surface area.

Dong et al. reported that RhB degradation ratio of g- $\mathrm{C}_{3} \mathrm{~N}_{4}$ samples is $100 \%$ after $300 \mathrm{~min}$ irradiation (RhB: $5 \mathrm{mg} \mathrm{L}{ }^{-1}, \mathrm{~g}$ $\mathrm{C}_{3} \mathrm{~N}_{4}$ : $0.9 \mathrm{~g} \mathrm{~L}^{-1}, 500 \mathrm{~W}$ Xe lamp). ${ }^{37}$ However, in our present work, $\mathrm{RhB}$ degradation ratio of $\mathrm{g}-\mathrm{C}_{3} \mathrm{~N}_{4}$ samples is almost $100 \%$ after $100 \mathrm{~min}$ irradiation (RhB: $10 \mathrm{mg} \mathrm{L}^{-1}, \mathrm{~g}_{-} \mathrm{C}_{3} \mathrm{~N}_{4}: 0.5 \mathrm{~g} \mathrm{~L}^{-1}, 400 \mathrm{~W}$ Metal halide lamp). At present, due to no unified photocatalytic experiment standard, it is difficult to keep the same test conditions for different researchers. The factors of pollutant concentration, catalyst dosage and the types and power of radiation sources etc. have great influence on photocatalytic degradation rate. It is generally believed that the higher contaminants concentration and catalyst dosage are, the better the degradation efficiency of contaminants is. Therefore, it can be concluded that the $\mathrm{g}-\mathrm{C}_{3} \mathrm{~N}_{4}$ samples prepared by our group have better photocatalytic performance.
Besides, the temporal absorption spectra changes of RhB in the presence of $S_{650-10}$ and $S_{600-10}$ samples are shown in Fig. 12c and $\mathrm{d}$. The declines of absorbances are mainly attributed to the degradation reaction of $\mathrm{RhB}$ catalyzed by $\mathrm{S}_{650-10}$ and $\mathrm{S}_{600-10}$ samples. These observations indicate that the whole conjugated chromophore structure of RhB undergo a facile cleavage. Notably, the concomitant slight hypsochromic shifts are observed, indicating that a de-ethylation process simultaneously occurrs. ${ }^{29}$ It can be seen from Fig. 12c, after $60 \mathrm{~min}$ irradiation, the maximum absorption wavelength shifts from $554 \mathrm{~nm}$ to $500 \mathrm{~nm}$. Moreover, in the course of experiment, we find the colour of the RhB solution turns to colourless after 60 min irradiation. This can be confirmed by the absorbance value at $554 \mathrm{~nm}$ in absorption spectrum curve. From Fig. 12d, we can find that the maximum absorption wavelength shifts to $516 \mathrm{~nm}$ after $60 \mathrm{~min}$ irradiation, and shifts to $498 \mathrm{~nm}$ after 80 min irradiation. It indicates that the degradation rate of $\mathrm{RhB}$ is different under the action of different catalyst samples. By the comparison of two absorption spectra, we can also conclude that $\mathrm{S}_{650-10}$ sample possesses more excellent photocatalytic activity than $\mathrm{S}_{600-10}$ sample.

The kinetic degradation curves of $\mathrm{RhB}$ in the presence of various samples are further analysed, as shown in Fig. 12e. The degradation rate constants of $\mathrm{RhB}$ are respectively $0.01272 \mathrm{~min}^{-1}\left(\mathrm{~S}_{500-10}\right), 0.01737 \mathrm{~min}^{-1}\left(\mathrm{~S}_{600-4}\right), 0.01912 \mathrm{~min}^{-1}$ $\left(\mathrm{S}_{550-10}\right), \quad 0.02073 \mathrm{~min}^{-1}\left(\mathrm{~S}_{600-6}\right), 0.02263 \mathrm{~min}^{-1}\left(\mathrm{~S}_{600-8}\right)$, $0.03069 \mathrm{~min}^{-1}\left(\mathrm{~S}_{600-10}\right)$ and $0.03854 \mathrm{~min}^{-1}\left(\mathrm{~S}_{650-10}\right)$ (Table 3). $\mathrm{S}_{650-10}$ sample possesses the highest photocatalytic degradation ability on RhB, and the degradation rate constant of RhB reaches $0.03854 \mathrm{~min}^{-1}$. However, the highest degradation rate constant of $\mathrm{RhB}$ over $\mathrm{g}-\mathrm{C}_{3} \mathrm{~N}_{4}$ reported by Dong et al. is only $0.0165 \mathrm{~min}^{-1} \cdot{ }^{37}$ These kinetics degradation curves basically conform to the first-order reaction kinetics process. In the later stage of degradation reaction, the phenomenon of deviation from first-order reaction kinetics occurs because of very low concentration of RhB.

The assessment of photochemical stability of photocatalysts is important for practical applications. The reusability tests over $\mathrm{S}_{650-10}$ sample are performed by carrying out five consecutive runs for the degradation of $\mathrm{RhB}$ under identical reaction conditions. The used samples are recycled by centrifugation, washed with ethanol and water for several times, and then dried at $60{ }^{\circ} \mathrm{C}$ for $2 \mathrm{~h}$. Five photocatalytic reaction runs of the $\mathrm{S}_{650-10}$ for RhB are shown in Fig. 12f. One can find that the degradation rate of $\mathrm{RhB}$ only decreases very slightly after five runs, indicating that $\mathrm{S}_{650-10}$ sample possesses excellent stability. Consequently, the as-prepared $\mathrm{g}-\mathrm{C}_{3} \mathrm{~N}_{4}$ is a promising visible light

Table 3 Rate constants of samples

\begin{tabular}{lllll}
\hline Samples & $\mathrm{S}_{500-10}$ & $\mathrm{~S}_{600-4}$ & $\mathrm{~S}_{550-10}$ & $\mathrm{~S}_{600-6}$ \\
Rate constants/ & 0.01272 & 0.01737 & 0.01912 & 0.02073 \\
min $^{-1}$ & & & & \\
Samples & $\mathrm{S}_{600-8}$ & $\mathrm{~S}_{600-10}$ & $\mathrm{~S}_{650-10}$ & \\
$\begin{array}{l}\text { Rate constants/ } \\
\min ^{-1}\end{array}$ & 0.02263 & 0.03069 & 0.03854 &
\end{tabular}


photocatalyst in the fields of air purification and wastewater treatment.

In addition, in order to provide usefulness for catalysts in the practical application, the photocatalytic experiment of $\mathrm{S}_{650-10}$ sample under natural sunlight is performed on the indoor windowsill (date: 5 October 2019, real time temperature of test location: $23-25^{\circ} \mathrm{C}$, longitude: 125.37 , latitude: 43.87$)$. The color change process of $\mathrm{RhB}$ over $\mathrm{S}_{650-10}$ sample under natural sunlight is recorded by digital photos and is shown in Fig. 12g. It can be clearly seen that the color of RhB turns from pink to colourless after $180 \mathrm{~min}$ under natural sunlight irradiation. The photocatalytic degradation curve of RhB is indicated in Fig. 12f. The degradation rate of $\mathrm{RhB}$ is almost $100 \%$ after $180 \mathrm{~min}$. Hence, the prepared $\mathrm{S}_{650-10}$ sample has practical application value.

The remarkably enhanced photocatalytic activities for $\mathrm{S}_{650-10}$ sample can be interpreted as the synergistic effects of the enhanced crystallinity, the large surface area, the reduced layer thickness and size, and the reduced number of defects. Firstly, the higher heat treatment temperature and the longer heat treatment time make the layer thickness and size of the asprepared g- $\mathrm{C}_{3} \mathrm{~N}_{4}$ reduced significantly, resulting in the evident quantum confinement effect. The quantum confinement effect makes the energy gap get widen, and the valence band potential become more positive and the conduction band potential become more negative, which effectively improve the redox ability of photogenerated holes and electrons. Moreover, the transport ability of photogenerated carriers in nanosheet is also enhanced and the separation efficiency of electron-hole pairs is improved. This higher separation efficiency could improve the probability of their involvement in photocatalytic reaction before recombination and enhance the photocatalytic activity. Secondly, the enlarged specific surface area could improve mass transfer ability and provide larger number of active redox reaction sites, which contributes to adsorbing abundant reactant molecules and promotes interfacial photocatalytic redox reactions with substrates. ${ }^{29}$ Finally, the higher crystallinity is advantageous to reduce the number of the defects. ${ }^{37}$ These favorable properties co-contribute to the improvement of photocatalytic activities of $\mathrm{g}-\mathrm{C}_{3} \mathrm{~N}_{4}$ nanosheets under visible light irradiation.

\section{Conclusions}

In summary, a facile template-free one-step synthesis method of ultrathin $\mathrm{g}-\mathrm{C}_{3} \mathrm{~N}_{4}$ nanosheets is developed though thermal polycondensation of melamine at $650^{\circ} \mathrm{C}$ for $10 \mathrm{~h}$. The ultrathin g- $\mathrm{C}_{3} \mathrm{~N}_{4}$ nanosheets with high yield of $25 \%$ are obtained at $650^{\circ} \mathrm{C}$ for $10 \mathrm{~h}$. The formation of ultrathin $\mathrm{g}-\mathrm{C}_{3} \mathrm{~N}_{4}$ nanosheets depends mainly on the higher heat treatment temperature, the longer heat treatment time and the retainable self-supporting ammonia generated from polycondensation reaction due to tightly sealed reaction system and low heating rate. The enhanced crystallinity, the large surface area, the reduced layer thickness and size, and the reduced number of defects cocontribute to the enhanced visible light photocatalytic activities of $\mathrm{g}^{-} \mathrm{C}_{3} \mathrm{~N}_{4}$ nanosheets. A new layer exfoliation and splitting mechanism of formation of the ultrathin nanosheets is proposed. The visible light photocatalytic activity of $\mathrm{g}-\mathrm{C}_{3} \mathrm{~N}_{4}$ nanosheets over RhB degradation are significantly improved as the heat treatment temperature is increased and the heat treatment time is prolonged. Moreover, $\mathrm{g}-\mathrm{C}_{3} \mathrm{~N}_{4}$ nanosheets have excellent photochemical stability. This work provides a new strategy to develop a facile eco-friendly template-free one-step synthesis method for potential large-scale synthesis of $\mathrm{g}-\mathrm{C}_{3} \mathrm{~N}_{4}$ nanosheets with high yield, high efficiency and stable activity for environmental and energetic applications.

\section{Conflicts of interest}

There are no conflicts of interest to declare.

\section{Acknowledgements}

This work was financially supported by the Industrial Technology Research and Development Projects of Jilin Province (Grant No. 2019C059), the Major Science and Technology Development Project of Changchun City (Grant No. 14KG079), the Science and Technology Development Project of Jilin Province (Grant No. 20180520217JH, 20170520152JH, 20170520153JH), and National Natural Science Foundation of China (Grant No. 51403075).

\section{Notes and references}

1 M. R. Hoffmann, S. T. Martin and W. Choi, Chem. Rev., 1995, 95, 69-96.

2 L. Nie and Q. Zhang, Inorg. Chem. Front., 2017, 4, 1953-1962.

3 G. Song, Z. Chu, W. Jin and H. Sun, Chin. J. Chem. Eng., 2015, 23, 1326-1334.

4 M. A. Khan, M. Xia, S. Mutahir and T. Muhmood, Catal. Sci. Technol., 2017, 7, 3017-3026.

5 J. Zhao, J. Yan, H. Jia, S. Zhong, X. Zhang and L. Xu, J. Mol. Catal. A: Chem., 2016, 424, 162-170.

6 A. Wang, C. Wang, L. Fu, W. Wong-Ng and Y. Lan, NanoMicro Lett., 2017, 9, 108-154.

7 W. Zhong, S. Shen, S. Feng, Z. Lin, Z. Wanga and B. Fang, CrystEngComm, 2018, 20, 7851-7856.

8 G. Liao, J. Fang, Q. Li, S. Li, Z. Xu and B. Fang, Nanoscale, 2019, 11, 7062-7096.

9 G. Liao, Y. Gong, L. Zhang, H. Gao, G.-J. Yang and B. Fang, Energy Environ. Sci., 2019, 12, 2080-2147.

10 J. Qin, J. Huo, P. Zhang, J. Zeng, T. Wang and H. Zeng, Nanoscale, 2016, 8, 2249-2259.

11 M. N. Nadagouda, R. B. N. Baig, R. S. Varma and S. Verma, ACS Sustainable Chem. Eng., 2016, 4, 1661-1664.

12 Y. Zhou, L. Zhang, W. Huang, Q. Kong, X. Fan, M. Wang and J. Shi, Carbon, 2016, 99, 111-117.

13 R. Wang, T. Yan, L. Han, G. Chen, H. Li, J. Zhang and D. Zhang, J. Mater. Chem. A, 2018, 6, 5752-5761.

14 Y. Li, X. Feng, Z. Lu, H. Yin, F. Liu and Q. Xiang, J. Colloid Interface Sci., 2018, 513, 866-876.

15 L. Cui, X. Ding, Y. Wang, H. Shi, L. Huang, Y. Zuo and S. Kang, Appl. Surf. Sci., 2017, 391, 202-210. 
16 X. Yuan, C. Zhou, Q. Jing, Q. Tang, Y. Mu and A. Du, Nanomaterials, 2016, 6, 173-184.

17 M. Shao, Y. Shao, J. Chai, Y. Qu, M. Yang, Z. Wang, M. Yang, W. F. Ip, C. T. Kwok, X. Shi, Z. Lu, S. Wang, X. Wang and H. Pan, J. Mater. Chem. A, 2017, 5, 16748-16759.

18 S. Wang, C. Li, T. Wang and P. Zhang, J. Mater. Chem. A, 2014, 2, 2885-2890.

19 Z. Tong, D. Yang, Z. Li, Y. Nan, F. Ding, Y. Shen and Z. Jiang, ACS Nano, 2017, 11, 1103-1112.

20 X. Bai, L. Wang, R. Zong and Y. Zhu, J. Phys. Chem. C, 2013, 117, 9952-9961.

21 S. Sun and S. Liang, Nanoscale, 2017, 9, 10544-10578.

22 K. Chen, Z. Chai, C. Li, L. Shi, M. Liu, Q. Xie, Y. Zhang, D. Xu, A. Manivannan and Z. Liu, ACS Nano, 2016, 10, 3665-3673.

23 X. Yuan, C. Zhou, Y. Jin, Q. Jing, Y. Yang, X. Shen and A.-K. Du, J. Colloid Interface Sci., 2016, 468, 211-219.

24 S. Wang, C. Li, T. Wang and P. Zhang, J. Mater. Chem. A, 2014, 2, 2885-2890.

25 M. Tahir, C. Cao, N. Mahmood, F. K. Butt, A. Mahmood, F. Idrees, S. Hussain, M. Tanvee, Z. Ali and I. Aslam, ACS Appl. Mater. Interfaces, 2013, 6, 1258-1265.

26 J. Wu, S. Yang, J. Li and Y. Yang, Adv. Opt. Mater., 2016, 4, 2095-2101.

27 X. Zhang, X. Xie, H. Wang, J. Zhang, B. Pan and Y. Xie, J. Am. Chem. Soc., 2013, 135, 18-21.

28 J. Xu, L. Zhang, R. Shi and Y. Zhu, J. Mater. Chem. A, 2013, 1, 14766-14772.

29 Q. Lin, L. Li, S. Liang, M. Liu, J. Bi and L. Wu, Appl. Catal., B, 2015, 163, 135-142.

30 J. Tong, L. Zhang, F. Li, K. Wang, L. Han and S. Cao, RSC Adv., 2015, 5, 88149-88153.

31 F. Dong, Y. Li, Z. Wang and W.-K. Ho, Appl. Surf. Sci., 2015, 358, 393-403.

32 P. Niu, L. Zhang, G. Liu and H. Cheng, Adv. Funct. Mater., 2012, 22, 4763-4770.
33 P. Qiu, H. Chen, C. Xu and N. Zhou, J. Mater. Chem. A, 2015, 3, 24237-24244.

34 Q. Liang, Z. Li, Z. H. Huang, F. Kang and Q. H. Yang, Adv. Funct. Mater., 2015, 25, 6885-6892.

35 K. S. Novoselov, A. K. Geim, S. V. Morozov, D. Jiang, Y. Zhang, S. V. Dubonos, I. V. Grigorieva and A. A. Firsov, Science, 2004, 306, 666-669.

36 J. Liu, T. Zhang, Z. Wang and G. Dawson, J. Mater. Chem., 2011, 21, 14398-14401.

37 F. Dong, Z. Wang, Y. Sun, W.-K. Ho and H. Zhang, J. Colloid Interface Sci., 2013, 401, 70-79.

38 M. Zhang, J. Xu, R. Zong and Y. Zhu, Appl. Catal., B, 2014, 147, 229-235.

39 F. He, G. Chen, Y. Yu, Y. Zhou, Y. Zheng and S. Hao, Chem. Commun., 2015, 51, 425-427.

40 V. Mahalingam and T. Biswas, New J. Chem., 2017, 41, 14839-14842.

41 X. Song, Q. Yang, M. Yin, D. Tang and L. Zhou, RSC Adv., 2018, 8, 7260-7268.

42 W. J. Ong, W.-J. Ong, L.-L. Tan, Y. H. Ng, S.-T. Yong and S.-P. Chai, Chem. Rev., 2016, 116(12), 7159-7329.

43 X. Wang, K. Maeda, A. Thomas, K. Takanabe, G. Xin, J. M. Carlsson and M. Antonietti, Nat. Mater., 2008, 8, 76-80. $44 \mathrm{X}$. Wang, X. Chen, A. Thomas, X. Fu and M. Antonietti, Adv. Mater., 2009, 21, 1609-1612.

45 F. Dong, Z. Wang, T. Xiong, Z. Ni, W. Zhang, Y. Sun and W.-K. Ho, ACS Appl. Mater. Interfaces, 2013, 5, 11392-11401.

46 J. Yu, S. Wang, J. Low and W. Xiao, Phys. Chem. Chem. Phys., 2013, 15, 16883-16890.

47 Z. Wang, W. Guan, Y. Sun, F. Dong, Y. Zhou and W.-K. Ho, Nanoscale, 2015, 7, 2471-2479.

48 Y. Yuan, W. Xu, L. Yin, S. Cao, Y. Liao, Y. Q. Tng and C. Xue, Int. J. Hydrogen Energy, 2013, 38, 13159-13163.

49 Q. Su, J. Sun, J. Wang, Z. Yang, W. Cheng and S. Zhang, Catal. Sci. Technol., 2014, 4, 1556-1567. 